\title{
Dipeptidyl peptidase-4(DPP-4) inhibitors: promising new agents for autoimmune diabetes
}

\author{
Xia Wang ${ }^{1,2,3} \cdot$ Peilin Zheng ${ }^{1,2} \cdot$ Gan Huang $^{1,2} \cdot$ Lin Yang $^{1,2} \cdot$ Zhiguang Zhou $^{1,2} \mathbb{C}$
}

Received: 14 May 2018 / Accepted: 8 July 2018 / Published online: 17 July 2018

(c) The Author(s) 2018

\begin{abstract}
Dipeptidyl peptidase-4 (DPP-4) inhibitors constitute a novel class of anti-diabetic agents confirmed to improve glycemic control and preserve $\beta$-cell function in type 2 diabetes. Three major large-scale studies, EXAMINE, SAVOR-TIMI 53, and TECOS, have confirmed the cardiovascular safety profile of DPP-4 inhibitors. Based on these results, DPP-4 inhibitors have gained widespread use in type 2 diabetes treatment. It is currently unknown, however, whether DPP-4 inhibitors have similar therapeutic efficacy against autoimmune diabetes. Several in vitro and in vivo studies have addressed this issue, but the results remain controversial. In this review, we summarize experimental findings and preliminary clinical trial results, and identify potentially effective immune modulation targets of DPP-4 inhibitors for autoimmune diabetes.
\end{abstract}

Keywords DPP-4 inhibitor · Incretin · Type 1 diabetes $\cdot$ Latent autoimmune diabetes in adults

\section{Introduction}

Autoimmune diabetes, including type 1 diabetes mellitus (T1DM) and latent autoimmune diabetes in adults (LADA), are caused mainly by autoimmune destruction of $\beta$-cells. Globally, LADA accounts for 4-12\% of diabetes cases [1]. The presence of islet autoantibodies, such as glutamic acid decarboxylase antibody 65 (GADA), insulin autoantibodies (IAAs), islet cell antibodies (ICAs), tyrosine phosphataserelated molecule-2 autoantibodies (IA2As), zinc transporter-8 autoantibodies (ZnT8As), and the newly identified tetraspanin 7 autoantibodies(TSPN7As) [2-8], strongly predicts the progression of overt autoimmune diabetes. Among them, GADA is undoubtedly the most critical autoantibody in autoimmune diabetes.

Zhiguang Zhou

zhouzhiguang@csu.edu.cn

1 Department of Metabolism and Endocrinology, The Second Xiangya Hospital, Central South University, Changsha, Hunan, China

2 Key Laboratory of Diabetes Immunology (Central South University), Ministry of Education, National Clinical Research Center for Metabolic Diseases, Changsha, Hunan, China

3 Department of Metabolism and Endocrinology, Hunan Provincial People's Hospital, Changsha, Hunan, China
Insulin is the most frequent treatment choice to compensate for the insufficiency in insulin secretion caused by $\beta$-cell dysfunction [9]. In addition to insulin, a variety of oral agents are prescribed for autoimmune diabetes, such as insulin sensitizers (metformin and thiazolidinediones), incretins, and sodium-glucose cotransporter inhibitors [10-12]. Dipeptidyl peptidase-4 (DPP-4) inhibitors, a new class of hypoglycemic agents, increase meal-time secretion of endogenous incretins (including glucagon-like peptide-1 and gastric inhibitory polypeptide) by blocking their degradation, decrease postprandial release of glucagon, and stimulate the secretion of insulin, thereby activating multiple hypoglycemic mechanisms. Three large-scale clinical trials, EXAMINE [13], SAVOR-TIMI 53 [14], and TECOS [15], have been completed since 2008 to assess the cardiovascular outcomes of DPP-4 inhibitors in type 2 diabetes. Although SAVOR-TIMI 53 found that the DPP-4 inhibitor saxagliptin increased hospitalizations for acute heart failure, several meta-analyses [16-18] have confirmed the cardiovascular (CV) safety of DPP-4 inhibitors. In addition to safety against adverse CV events, DPP-4 inhibitors demonstrate weight neutrality and a low incidence of hypoglycemia, and thus have gained broad application in clinical practice [19].

Apart from specific hypoglycemic mechanisms, DPP-4 inhibitors possess an immune modulation profile, offering the potential for extendibility to autoimmune diabetes. Autoimmune diabetes is associated with marked alterations 
in the frequencies of circulating immune cells, including $\mathrm{T}$ cells [20], B cells [21], natural killer cells [22], and dendritic cells [23]. Among these, effector T cells (Teff) are considered crucial for the progression of autoimmune diabetes. In non-obese diabetic (NOD) mice, DPP-4 inhibitors decreased the type 1 helper T cell (Th1) immune response, upregulated secretion of Th2 anti-inflammatory cytokines, activated $\mathrm{CD} 4{ }^{+} \mathrm{CD} 25^{+} \mathrm{FoxP}_{3}{ }^{+}$regulatory $\mathrm{T}$ cells, and prevented production of the pro-inflammatory cytokine IL-17 [24]. Accordingly, we speculate that DPP-4 inhibitors may also attenuate the autoimmune processes underlying autoimmune diabetes. In this review, we summarize the physiological and immunomodulatory effects of DPP-4 inhibitors, and discuss potential applications for the treatment of autoimmune diabetes.

\section{Overview of DPP-4 biology}

Dipeptidyl peptidase-4, also known as cluster of differentiation antigen 26 (CD26), is a widely expressed and highly conserved membrane glycoprotein that cleaves $\mathrm{N}$-terminal dipeptides from proteins with proline or alanine in the penultimate position. It is strongly expressed on the membranes of specialized cell types within liver, kidney, lung, spleen, and pancreas, including adipocytes, hepatocytes, endothelial cells, and epithelial cells, and is implicated in their physiological functions. It is also broadly expressed on various immune cells including T, B, and NK cells, macrophages, and dendritic cells [25]. Many regulatory peptides containing the CD26 target sequence are cleaved and inactivated by this enzyme, including incretin peptides such as glucagonlike peptide-1 (GLP-1), GLP-2, and gastric inhibitory polypeptide (GIP), as well as brain natriuretic peptide (BNP), peptide YY, stromal cell-derived factor-1 (SDF-1), and substance P. The diversity of substrates degraded by DPP-4 expands its actions, both physiological and pathological, and indeed DPP-4 is implicated in diabetes, solid tumor development, autoimmune diseases, and obesity [26].

CD26 also regulates multiple aspects of lymphocyte function independent of enzymatic activity [27]. It is the main cellular binding protein for ecto-adenosine deaminase (eADA), which is responsible for the degradation of adenosine. It also binds extracellular matrix (ECM) components such as collagen and fibronectin, thereby regulating the interactions of various cells with the ECM, including cancer cells. More germane to autoimmune diabetes, CD26 regulates $\mathrm{T}$ cell activation and immune signaling pathways by associating with the chemokine receptor CXCR4 and the serine protease fibroblast activated protein-alpha (FAP- $\alpha$ ). In addition to its membrane-anchored form, DPP-4 also has a soluble form in plasma that is observed in certain cancers, autoimmune diseases, diabetes, and obesity.
While DPP4 inhibitors share common modes of action, there is still prominent heterogeneity in pharmacokinetic properties among compounds, such as differences in halflife, biological activity, metabolism, and excretion. Some DPP-4 inhibitors are substrate-enzymatic blockers (saxagliptin and vildagliptin), while others are competitive inhibitors (sitagliptin and alogliptin) [28]. Inhibitors of DPP-4 also differ in the route of elimination. For instance, most DPP-4 inhibitions are eliminated mainly through the kidney while less than $5 \%$ of linagliptin is eliminated through this route.

\section{Functions of $T$ cell subsets Th1, Th2, Treg, Th17, and $\mathrm{CDB}^{+}$in immune modulation}

Helper T (Th) cell subsets are distinguished by the different cytokines produced and major transcription factor expressed. Type 1 Th cells contribute to cell-mediated immune modulation, while Th2 cells promote humoral immunity. These two subsets exert reciprocal control over the function of the other. Thus, Th1/Th2 balance is a critical factor for induction and modulation of immune pathology in autoimmune diabetes. The helper $\mathrm{T}$ cell subset Th17 producing interleukin-17 (IL-17) has emerged as an important contributor to pathological conditions that were previously attributed to Th1 cells. Moreover, $\mathrm{CD} 4^{+} \mathrm{CD} 25^{+} \mathrm{T}$ regulatory cells (Tregs) appear critical for mediating Th17 activity and Th17/Treg balance [29].

Type 1 Th populations secreting pro-inflammatory cytokines such as IL-2 and interferon- $\gamma$ (IFN- $\gamma$ ) are crucial mediators of $\beta$-cell autoreactivity. Higher levels of Th1related cytokines were observed in children at greater risk of developing T1DM [30]. On the contrary, Th2 populations producing cytokines such as IL-4, IL-5, and IL-13 possess a crucial protective profile against autoimmunity in T1DM. The most important immune regulators are Tregs [31]. They can suppress the proliferation and function of Teff cells, and maintain immune balance. Forkhead transcription factor P3 (FoxP3), a specific marker of Treg cells, controls their differentiation and function. Patients with T1DM exhibit decreased Treg frequency [32], and this defect in Treg number and/or function is a major factor in disease progression [33-35]. Dysfunction of Tregs is also observed in LADA [36] as evidenced by significantly reduced expression of FoxP3 and a hypermethylated FoxP3 promoter region in $\mathrm{CD}^{+}{ }^{+} \mathrm{T}$ cells [37]. Treatment with Tregs is considered safe and effective for preserving $\beta$-cell function in T1DM $[38,39]$.

The IL-17-producing Th17 cell, a novel class of $\mathrm{CD} 4^{+} \mathrm{T}$ cell with specificity for self-antigens [40], are extremely pathogenic and result in multiple severe inflammatory and autoimmune disorders [41-43]. Several studies have found substantially elevated IL-17 in T1DM patients [44-46]. In 
rodent models, plasticity of the Th1/Th17 cell balance has been implicated as a potential contributor to the progression of autoimmune diabetes [47].

In addition to $\mathrm{CD} 4^{+} \mathrm{T}$ cells, there is growing evidence for the involvement of $\mathrm{CD} 8^{+} \mathrm{T}$ cells in T1DM pathogenesis [48-50]. These autoreactive $\mathrm{CD} 8^{+} \mathrm{T}$ cells can be found in the peripheral blood of T1DM patients [51], and reflect a novel and distinctive feature in immunopathogenesis. TGF- $\beta$ can reduce apoptosis of differentiated autoreactive $\mathrm{CD} 8^{+} \mathrm{T}$-cells, thereby promoting their expansion and infiltration into islets [9]. The use of non-depleting antibodies specific for $\mathrm{CD} 4^{+}$ and $\mathrm{CD}^{+}$resulted in long-term diabetes remission in NOD transgenic mice [52], while immunotargeting of insulinreactive $\mathrm{CD} 8^{+} \mathrm{T}$ cells in young NOD mice reduced disease incidence and slowed progression [53], thus providing a possible immunotherapy for T1DM.

In NOD mice, sitagliptin [54] decreased migration of splenic and lymph node $\mathrm{CD} 4^{+} \mathrm{T}$ cells through incretindependent and -independent pathways, suggesting that the anti-diabetic response may be mediated through selective effects on $\mathrm{T}$ cell subsets associated with autoimmunity. In CD26 knockout mice, a DPP-4 inhibitor upregulated Th2 and Treg cells, and suppressed the pathogenic effects of Th1 and Th17 cells [55]. In an in vivo study [24], a DPP-4 inhibitor demonstrated an immunosuppressive effect on Th1 and Th17 lymphocyte differentiation, and led to the generation of regulatory transforming growth factor (TGF- $\beta 1$ ) and reduced CD26 gene expression, which help maintain the survival of pancreatic $\beta$-cells. In addition, CD26 is highly expressed on Th17 cells [56]; moreover, DPP-4 inhibition can prevent the production of IL-17 in NOD mice [57, 58], underscoring the potential of DPP-4 inhibitors as therapeutic agents to suppress the pathogenic effects of Th17 cells in autoimmune diabetes. Further, the frequency of the $\mathrm{CD} 8^{+} \mathrm{T}$ lymphocyte subset was enhanced, the inflammatory response suppressed, and diabetes onset delayed or prevented by a DPP-4 inhibitor in NOD mice [59].

DPP-4 is highly expressed on T cells and regulates their biological function. The immune responses of Th1 cells were deregulated, IFN- $\gamma$ was suppressed, and Th 2 cytokines such as IL-4, IL-5, and IL-13 were upregulated in CD26 knockout mice [55]. Suppression of DPP-4 also reduced production of IL-2, IL-12, and IFN- $\gamma$ by T cells and peripheral blood mononuclear cells (PBMC) [60, 61]. The expression of TGF- $\beta$ was shown to be downregulated in T1DM patients [62]. Alternatively, TGF- $\beta$-activated kinase-1 (TAK1, Map3k7) can increase the production of TGF- $\beta$ and delay the onset of autoimmune diabetes in NOD mice [63, 64]. DPP-4 inhibition can upregulate the level of TGF- $\beta[24,65]$ and stromal cell-derived factor-1 (SDF-1) in vitro $[66,67]$. Thus, DPP-4 inhibition may slow the progression of diabetes by shifting the balance toward anti-inflammatory $\mathrm{T}$ cell subsets and cytokines (Table 1).
Table 1 Effect of DPP4 inhibition on T cell subsets and cytokines

\begin{tabular}{|c|c|}
\hline $\mathrm{T}$ cell subsets & Cytokines \\
\hline Th1 $\downarrow[24,55]$ & IL- $2 \downarrow[60,61]$, IFN- $\gamma \downarrow[60,61] ;$ TNF- $\alpha \downarrow[68] ;$ \\
\hline $\operatorname{Th} 2 \uparrow[24,55]$ & 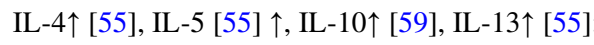 \\
\hline 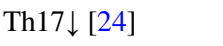 & 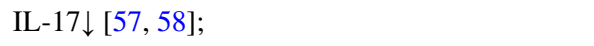 \\
\hline $\operatorname{Treg} \uparrow[24,65,69]$ & TGF- $\beta \uparrow[24,65]$ \\
\hline \multirow[t]{2}{*}{$\mathrm{CD}^{+} \uparrow[59]$} & IL-10个 [59]; \\
\hline & 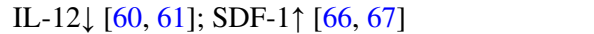 \\
\hline
\end{tabular}

Treg regulatory $\mathrm{T}$ cell, $I F N$ interferon, $I L$ interleukin, $T G F$ transforming growth factor, $S D F-1$ stromal cell-derived factor-1, $\uparrow$ upregulation, $\downarrow$ downregulation

\section{Preclinical effects of DPP4 inhibitor in autoimmune diabetes}

Administration of DPP-4 inhibitors can inhibit inflammatory signaling pathways $[70,71]$ mediating vascular smooth cell proliferation and oxidative stress in various cells types [72], and also appears to improve endothelial function, blood pressure, and lipid metabolism in T2DM [73]. Of special note, emerging evidence suggests that DPP-4 inhibition can protect against myocardial infarction and atherosclerosis [74-77]. In conclusion, these studies consistently demonstrate that DPP4 inhibition provides endothelial protection through suppression of inflammation. Thus, aside from improving metabolic control [78], DPP4 inhibitors can suppress autoimmune processes leading to diabetic vasculopathy.

Inhibition of DPP-4 induced islet neogenesis, $\beta$-cell regeneration, and insulin synthesis in streptozotocin (STZ) model diabetic mice [79]. DPP-4 inhibitors can also preserve pancreatic $\beta$-cell mass and protect $\beta$-cells not only in diabetes rodent models $[80,81]$ but also in impaired fasting glucose patients and diabetes patient $[82,83]$. DPP-4 inhibitors were also found to improve islet graft survival $[84,85]$ and even delay the onset of autoimmune diabetes in NOD mice $[65,86]$.

DPP-4 inhibitors may also act synergistically with other anti-diabetes treatments. Combination therapy with a DPP-4 inhibitor and a proton-pump inhibitor (PPI) raised blood concentrations of gastrin, promoted $\beta$-cell neogenesis, attenuated insulitis, and re-establish normoglycemia in NOD mice $[87,88]$. The combination of a DPP-4 inhibitor and Toll-like receptor 2 agonist also increased $\beta$-cell mass in NOD mice with new onset diabetes [89]. The combination of a DPP-4 inhibitor and angiotensin II receptor blocker promoted islet regeneration [90]. Moreover, the combination of a DPP-4 inhibitor with a histone deacetylase inhibitor [91], VitD3 [60], or low-dose monoclonal CD3 antibody [69] has shown benefits as adjunct therapy for T1DM prevention in NOD mice. Thus, we postulate that combination therapy 
including a DPP-4 inhibitor can directly promote the growth and survival of $\beta$-cells in patients with autoimmune diabetes.

\section{Clinical effects of DPP-4 inhibitor on autoimmune diabetes}

Several case reports [92-95] on autoimmune diabetes patients have found that DPP-4 inhibitor treatment, alone or in combination with other drugs, significantly improved glucose control and reduced insulin requirements, with a good tolerance profile. Therefore, DPP-4 inhibitors may also benefit autoimmune diabetes. Nevertheless, the current level of evidence is of limited quality. There have been several smallscale randomized, controlled clinical pilot trials on DPP-4 inhibitors for autoimmune diabetes [96-101] (Table 2). Incretin-based therapy in T1DM patients improved glycemic control and reduced both hypoglycemia incidence and insulin requirements. However, there are discrepancies among these trials regarding efficacy of glycemic control, attenuation of $\beta$-cell function, and hypoglycemia frequency. Four studies $[96,98,100,101]$ found that DPP-4 inhibition can decrease required insulin dose, improve overall glucose control, and attenuate the decline in C-peptide levels. In contrast, another study [102] concluded that co-therapy with a DPP-4 inhibitor does not reduce the frequency of hypoglycemia in C-peptide-negative T1DM. However, a post hoc analysis from 5 pooled RCTs [103] found that saxagliptin was effective in decreasing blood glucose levels in GADApositive patients and tended to improve $\beta$-cell function during a 24-week follow-up. Furthermore, an associated metaanalysis [104] concluded that DPP-4 inhibition significantly reduces daily insulin dose in T1DM.

There are several limitations to these clinical trials. First, due to the low incidence of T1DM, the enrolled sample sizes were small, most of them were pilot studies, and longterm large-scale prospective study is still lacking. Second, diabetes duration differed obviously among these studies, with some restricted to newly diagnosed T1DM while others included long-term autoimmune diabetes with exhausted C-peptide function, which would reduce the potential benefits of DPP-4 inhibition. Thus, the residual $\beta$ cell function as a criteria for autoimmune diabetes patients selection seems to be the key point. Third, the follow-up period varied from 8 weeks to 2 years, insufficient to observe possible long-term efficacy. A four-year pilot study suggested that sitagliptin may be more effective for preserving $\beta$-cell function through immune modulation than insulin replacement [105], highlighting the promise of DPP-4 inhibitors for prevention or slowing the progression of autoimmune diabetes.

In all of these pilot trials, however, the number of cases with autoimmune diabetes was small, so large-scale and multi-center RCTs are needed to confirm the efficacy of DPP-4 inhibitors. Three large-scale RTCs on DPP-4 inhibitors for LADA or T1D are currently ongoing (Table 2). Two of these studies (NCT02307695 and NCT02407899) are being conducted in China and currently recruiting patients, while the other in Norway (NCT01140438) is active but not yet recruiting (Table 3 ).

\section{Safety and efficacy of DPP-4 inhibitors in autoimmune diabetes}

Several completed clinical trials $[26,84,103,106]$ have evaluated the safety and efficacy of DPP-4 inhibitors in T1DM. Neither severe hypoglycemic events nor serious side effects were observed. Minor side effects included gastrointestinal reactions (vomiting, diarrhea, nausea, etc.), flulike symptoms, and skin reactions [101]. A meta-analysis [104] including 228 T1DM patients concluded that DPP-4 inhibitors combined with insulin do not increase or decrease the risk of hypoglycemia. The RCTs in progress should provide additional information on potential adverse effects and other safety concerns.

Table 2 Clinical trials of dipeptidyl peptidase-4 inhibitors for autoimmune diabetes

\begin{tabular}{lrlllll}
\hline $\begin{array}{l}\text { Name (Clini- } \\
\text { calTrials.gov } \\
\text { identifier) }\end{array}$ & N & Age (years) & Design & Duration & Type of patients & Intervention \\
\hline NCT00978796 & 19 & $18-70$ & Double-blind RCT & 8-Week & Adult T1D & $\begin{array}{c}\text { Insulin with sitagliptin or without } \\
\text { sitagliptin }\end{array}$ \\
& 125 & $18-70$ & Multicentre double-blind RCT & 20-Week & T1D & Sitagliptin \\
NCT01227460 & 12 & $18-70$ & Open-label RCT & 1-Year & Adult T1D & Insulin with sitagliptin or exenatide 4 \\
NCT01235819 & 58 & $11-36$ & Multicentre RCT & 1-Year & T1D & Sitagliptin + lansoprazole \\
NCT01155284 & 18 & $18-80$ & Double-blind RCT & 2-Year & LADA & Linagliptin versus glimepiride \\
NCT00622284 & 30 & $25-70$ & Open-label RCT & 1-Year & LADA & Insulin with sitagliptin or without \\
NCT01159847 & & & & & & 4 \\
\end{tabular}

$R C T$ randomized clinical trial 
Table 3 Ongoing clinical trials of dipeptidyl peptidase-4 inhibitors for autoimmune diabetes

\begin{tabular}{lrllllll}
\hline $\begin{array}{l}\text { Name (ClinicalTri- } \\
\text { als.gov identifier) }\end{array}$ & $\mathrm{n}$ & Design & Time & Intervention & Phase & Country & Estimated end date \\
\hline NCT02307695 & 184 & Open-label RCT & 24-Week & Saxagliptin + insulin & 4 & China & March 2017 \\
NCT02407899 & 300 & Open-label RCT & 104-Week & Saxagliptin or (and) vitamin D3 + insulin & 4 & China & June 2018 \\
NCT01140438 & 78 & Open-label RCT & 104-Week & $\begin{array}{c}\text { Metformin + NPH, or metformin + sitag- } \\
\text { liptin } \pm \text { repaglinide }\end{array}$ & Norway & December 2018 \\
\hline
\end{tabular}

$N P H$ neutral protamine hagedorn insulin

\section{Conclusions}

In summary, DPP-4 inhibitors act as potent immune modulators through regulation of $\mathrm{T}$ cell phenotype and cytokine secretion. They are demonstrated to improve blood glucose control and attenuate $\beta$-cell destruction in animal models of autoimmune diabetes. In addition, DPP-4 inhibitors have shown good safe profiles not only in preclinical studies but also in randomized controlled clinical trials for autoimmune diabetes treatment. Collectively, these observations indicate that DPP-4 inhibitors are promising therapeutics for autoimmune diabetes. Though we are cautious on the use of DPP4 inhibitors in adults with autoimmune diabetes and no recommendations can be given at present time, further largescale cohort studies are warranted to validate the therapeutic efficacy and safety of DPP-4 inhibitors in the near future.

Acknowledgements The authors thank Professors Peilin Zheng, Gan Huang, Lin Yang, and Zhiguang Zhou (Diabetes Center, Institute of Metabolism and Endocrinology, The Second Xiangya Hospital of Central South University) for critically revising the manuscript.

Funding Our work was sponsored by the National Key R\&D Program of China (2016YFC1305000, 2016YFC1305001), the National Science and Technology Infrastructure Program (2015BAI12B13), the National Natural Science Foundation of China (81170725, 81070627, 81500600,8146168031 ), and the Key Project of Chinese Ministry of Education (113050A).

\section{Compliance with ethical standards}

Conflict of interest The authors declare no conflicts of interest.

Open Access This article is distributed under the terms of the Creative Commons Attribution 4.0 International License (http://creativeco mmons.org/licenses/by/4.0/), which permits unrestricted use, distribution, and reproduction in any medium, provided you give appropriate credit to the original author(s) and the source, provide a link to the Creative Commons license, and indicate if changes were made.

\section{References}

1. Zhou Z, Xiang Y, Ji L, et al. Frequency, immunogenetics, and clinical characteristics of latent autoimmune diabetes in China (LADA China study): a nationwide, multicenter, clinic-based cross-sectional study. Diabetes. 2013;62(2):543-50.

2. Andersson C, Kolmodin M, Ivarsson SA, et al. Islet cell antibodies (ICA) identify autoimmunity in children with new onset diabetes mellitus negative for other islet cell antibodies. Pediatr Diabetes. 2014;15(5):336-44.

3. Borg H, Fernlund P, Sundkvist G. Protein tyrosine phosphatase-like protein IA2-antibodies plus glutamic acid decarboxylase 65 antibodies (GADA) indicates autoimmunity as frequently as islet cell antibodies assay in children with recently diagnosed diabetes mellitus. Clin Chem. 1997;43(12):2358-63.

4. Bottazzo GF, Bosi E, Cull CA, et al. IA-2 antibody prevalence and risk assessment of early insulin requirement in subjects presenting with type 2 diabetes (UKPDS 71). Diabetologia. 2005;48(4):703-8.

5. Huang G, Wang X, Li Z, Li H, Li X, Zhou Z. Insulin autoantibody could help to screen latent autoimmune diabetes in adults in phenotypic type 2 diabetes mellitus in Chinese. Acta Diabetol. 2010;49(5):327-31.

6. Huang G, Xiang Y, Pan L, Li X, Luo S, Zhou Z. Zinc transporter 8 autoantibody (ZnT8A) could help differentiate latent autoimmune diabetes in adults (LADA) from phenotypic type 2 diabetes mellitus. Diabetes Metab Res Rev. 2013;29(5):363-8.

7. McLaughlin KA, Richardson CC, Ravishankar A, et al. Identification of tetraspanin-7 as a target of autoantibodies in type 1 diabetes. Diabetes. 2016;65(6):1690-8.

8. Walther D, Eugster A, Jergens S, et al. Tetraspanin 7 autoantibodies in type 1 diabetes. Diabetologia. 2016;59(9):1973-6.

9. Tiittanen M, Huupponen JT, Knip M, Vaarala O. Insulin treatment in patients with type 1 diabetes induces upregulation of regulatory T-cell markers in peripheral blood mononuclear cells stimulated with insulin in vitro. Diabetes. 2006;55(12):3446-54.

10. Guglielmi C, Palermo A, Pozzilli P. Latent autoimmune diabetes in the adults (LADA) in Asia: from pathogenesis and epidemiology to therapy. Diabetes Metab Res Rev. 2012;28(Suppl 2):40-6.

11. Yang Z, Zhou Z, Li X, Huang G, Lin J. Rosiglitazone preserves islet beta-cell function of adult-onset latent autoimmune diabetes in 3 years follow-up study. Diabetes Res Clin Pract. 2009;83(1):54-60.

12. Frandsen CS, Dejgaard TF, Madsbad S. Non-insulin drugs to treat hyperglycaemia in type 1 diabetes mellitus. Lancet Diabetes Endocrinol. 2016;4(9):766-80.

13. White WB, Cannon CP, Heller SR, et al. Alogliptin after acute coronary syndrome in patients with type 2 diabetes. N Engl J Med. 2013;369(14):1327-35. 
14. Scirica BM, Bhatt DL, Braunwald E, et al. Saxagliptin and cardiovascular outcomes in patients with type 2 diabetes mellitus. N Engl J Med. 2013;369(14):1317-26.

15. Green JB, Bethel MA, Armstrong PW, et al. Effect of sitagliptin on cardiovascular outcomes in type 2 diabetes. N Engl J Med. 2015;373(3):232-42.

16. Kim SC, Glynn RJ, Liu J, Everett BM, Goldfine AB. Dipeptidyl peptidase- 4 inhibitors do not increase the risk of cardiovascular events in type 2 diabetes: a cohort study. Acta Diabetol. 2014;51(6):1015-23.

17. Monami M, Ahren B, Dicembrini I, Mannucci E. Dipeptidyl peptidase- 4 inhibitors and cardiovascular risk: a metaanalysis of randomized clinical trials. Diabetes Obes Metab. 2013;15(2):112-20.

18. Xia C, Goud A, D'Souza J, et al. DPP4 inhibitors and cardiovascular outcomes: safety on heart failure. Heart Fail Rev. 2017;22(3):299-304.

19. Baetta R, Corsini A. Pharmacology of dipeptidyl peptidase-4 inhibitors: similarities and differences. Drugs. 2011;71(11):1441-67.

20. Radenkovic M, Silver C, Arvastsson J, et al. Altered regulatory $\mathrm{T}$ cell phenotype in latent autoimmune diabetes of the adults (LADA). Clin Exp Immunol. 2016;186(1):46-56.

21. Deng C, Xiang Y, Tan T, et al. Altered peripheral B-lymphocyte subsets in type 1 diabetes and latent autoimmune diabetes in adults. Diabetes Care. 2016;39(3):434-40.

22. Akesson C, Uvebrant K, Oderup C, et al. Altered natural killer (NK) cell frequency and phenotype in latent autoimmune diabetes in adults (LADA) prior to insulin deficiency. Clin Exp Immunol. 2010;161(1):48-56.

23. Nieminen JK, Vakkila J, Salo HM, et al. Altered phenotype of peripheral blood dendritic cells in pediatric type 1 diabetes. Diabetes Care. 2012;35(11):2303-10.

24. Pinheiro MM, Stoppa CL, Valduga CJ, et al. Sitagliptin inhibit human lymphocytes proliferation and Th1/Th17 differentiation in vitro. Eur J Pharm Sci. 2017;100:17-24.

25. Gorrell MD. Dipeptidyl peptidase IV and related enzymes in cell biology and liver disorders. Clin Sci (Lond). 2005;108(4):277-92.

26. Zhao Y, Yang L, Zhou Z. Dipeptidyl peptidase-4 inhibitors: multitarget drugs, not only antidiabetes drugs. J Diabetes. 2014;6(1):21-9.

27. Zhong J, Gong Q, Goud A, Srinivasamaharaj S, Rajagopalan $\mathrm{S}$. Recent advances in dipeptidyl-peptidase-4 inhibition therapy: lessons from the bench and clinical trials. J Diabetes Res. 2015;2015:606031.

28. Scheen AJ. A review of gliptins for 2014. Expert Opin Pharmacother. 2015;16(1):43-62.

29. Astry B, Venkatesha SH, Moudgil KD. Involvement of the IL-23/IL-17 axis and the Th17/Treg balance in the pathogenesis and control of autoimmune arthritis. Cytokine. 2015;74(1):54-61.

30. Stechova K, Bohmova K, Vrabelova Z, et al. High T-helper-1 cytokines but low T-helper-3 cytokines, inflammatory cytokines and chemokines in children with high risk of developing type 1 diabetes. Diabetes Metab Res Rev. 2007;23(6):462-71.

31. Hull CM, Peakman M, Tree TIM. Regulatory T cell dysfunction in type 1 diabetes: what's broken and how can we fix it? Diabetologia. 2017;60(10):1839-50.

32. Qiao YC, Shen J, Hong XZ, et al. Changes of regulatory T cells, transforming growth factor-beta and interleukin-10 in patients with type 1 diabetes mellitus: a systematic review and metaanalysis. Clin Immunol. 2016;170:61-9.

33. Ryba-Stanislawowska M, Rybarczyk-Kapturska K, Mysliwiec M, Mysliwska J. Elevated levels of serum IL-12 and IL-18 are associated with lower frequencies of CD4(+)CD25 (high)FOXP3 $(+)$ regulatory $t$ cells in young patients with type 1 diabetes. Inflammation. 2014;37(5):1513-20.

34. Bin Dhuban K, Kornete M, Edward SM, Piccirillo CA. Functional dynamics of Foxp3(+) regulatory $\mathrm{T}$ cells in mice and humans. Immunol Rev. 2014;259(1):140-58.

35. Lindley S, Dayan CM, Bishop A, Roep BO, Peakman M, Tree TI. Defective suppressor function in CD4(+)CD25(+) T-cells from patients with type 1 diabetes. Diabetes. 2005;54(1):92-9.

36. Yang Z, Zhou Z, Huang G, et al. The CD4(+) regulatory T-cells is decreased in adults with latent autoimmune diabetes. Diabetes Res Clin Pract. 2007;76(1):126-31.

37. Li Y, Zhao M, Hou C, et al. Abnormal DNA methylation in $\mathrm{CD} 4+\mathrm{T}$ cells from people with latent autoimmune diabetes in adults. Diabetes Res Clin Pract. 2011;94(2):242-8.

38. Cabrera SM, Rigby MR, Mirmira RG. Targeting regulatory $\mathrm{T}$ cells in the treatment of type 1 diabetes mellitus. Curr Mol Med. 2012;12(10):1261-72.

39. Marek-Trzonkowska N, Mysliwiec M, Dobyszuk A, et al. Administration of CD4 + CD25highCD127- regulatory T cells preserves beta-cell function in type 1 diabetes in children. Diabetes Care. 2012;35(9):1817-20.

40. Bettelli E, Korn T, Kuchroo VK. Th17: the third member of the effector T cell trilogy. Curr Opin Immunol. 2007;19(6):652-7.

41. Fores JP, Crisostomo LG, Orii NM, et al. Th17 pathway in recent-onset autoimmune diabetes. Cell Immunol. 2017;324:8-13.

42. Kumar P, Subramaniyam G. Molecular underpinnings of Th17 immune-regulation and their implications in autoimmune diabetes. Cytokine. 2015;71(2):366-76.

43. Shao S, He F, Yang Y, Yuan G, Zhang M, Yu X. Th17 cells in type 1 diabetes. Cell Immunol. 2012;280(1):16-21.

44. Marwaha AK, Crome SQ, Panagiotopoulos C, et al. Cutting edge: increased IL-17-secreting T cells in children with new-onset type 1 diabetes. J Immunol. 2010;185(7):3814-8.

45. Ferraro A, Socci C, Stabilini A, et al. Expansion of Th17 cells and functional defects in $\mathrm{T}$ regulatory cells are key features of the pancreatic lymph nodes in patients with type 1 diabetes. Diabetes. 2011;60(11):2903-13.

46. Baharlou R, Ahmadi-Vasmehjani A, Davami MH, et al. Elevated levels of T-helper 17-associated cytokines in diabetes type $\mathrm{i}$ patients: indicators for following the course of disease. Immunol Invest. 2016;45(7):641-51.

47. Reinert-Hartwall L, Honkanen J, Salo HM, et al. Th1/Th17 plasticity is a marker of advanced beta cell autoimmunity and impaired glucose tolerance in humans. J Immunol. 2015;194(1):68-75.

48. Tsai S, Shameli A, Santamaria P. CD8 + T cells in type 1 diabetes. Adv Immunol. 2008;100:79-124.

49. Hamel Y, Mauvais FX, Pham HP, et al. A unique CD8(+) T lymphocyte signature in pediatric type 1 diabetes. J Autoimmun. 2016;73:54-63.

50. Mallone R, Martinuzzi E, Blancou P, et al. CD8+T-cell responses identify beta-cell autoimmunity in human type 1 diabetes. Diabetes. 2007;56(3):613-21.

51. Skowera A, Ladell K, McLaren JE, et al. beta-cell-specific CD8 $\mathrm{T}$ cell phenotype in type 1 diabetes reflects chronic autoantigen exposure. Diabetes. 2015;64(3):916-25.

52. Yi Z, Diz R, Martin AJ, et al. Long-term remission of diabetes in NOD mice is induced by nondepleting anti-CD4 and anti-CD8 antibodies. Diabetes. 2012;61(11):2871-80.

53. Scott GS, Fishman S, Khai Siew L, et al. Immunotargeting of insulin reactive CD8 T cells to prevent diabetes. J Autoimmun. 2010;35(4):390-7.

54. Kim SJ, Nian C, McIntosh CH. Sitagliptin (MK0431) inhibition of dipeptidyl peptidase IV decreases nonobese diabetic mouse 
CD4 + T-cell migration through incretin-dependent and -independent pathways. Diabetes. 2010;59(7):1739-50.

55. Yan S, Gessner R, Dietel C, Schmiedek U, Fan H. Enhanced ovalbumin-induced airway inflammation in CD26-/- mice. Eur J Immunol. 2012;42(2):533-40.

56. Bengsch B, Seigel B, Flecken T, Wolanski J, Blum HE, Thimme R. Human Th17 cells express high levels of enzymatically active dipeptidylpeptidase IV (CD26). J Immunol. 2012;188(11):5438-47.

57. Emamaullee JA, Davis J, Merani S, et al. Inhibition of Th17 cells regulates autoimmune diabetes in NOD mice. Diabetes. 2009;58(6):1302-11.

58. Honkanen J, Nieminen JK, Gao R, et al. IL-17 immunity in human type 1 diabetes. J Immunol. 2010;185(3):1959-67.

59. Alonso N, Julian MT, Carrascal J, et al. Type 1 diabetes prevention in NOD mice by targeting DPPIV/CD26 is associated with changes in CD8(+)T effector memory subset. PLoS ONE. 2015;10(11):e0142186.

60. Pinheiro MM, Pinheiro FMM, Trabachin ML. Dipeptidyl peptidase-4 inhibitors (DPP-4i) combined with vitamin D3: an exploration to treat new-onset type 1 diabetes mellitus and latent autoimmune diabetes in adults in the future. Int Immunopharmacol. 2018;57:11-7.

61. Shah P, Ardestani A, Dharmadhikari G, et al. The DPP-4 inhibitor linagliptin restores beta-cell function and survival in human isolated islets through GLP-1 stabilization. J Clin Endocrinol Metab. 2013;98(7):E1163-72.

62. Abbasi F, Amiri P, Sayahpour FA, et al. TGF-beta and IL-23 gene expression in unstimulated PBMCs of patients with diabetes. Endocrine. 2012;41(3):430-4.

63. Cao H, Lu J, Du J, et al. TAK1 inhibition prevents the development of autoimmune diabetes in NOD mice. Sci Rep. 2015;5:14593.

64. Olivieri A, De Angelis S, Dionisi S, et al. Serum transforming growth factor betal during diabetes development in non-obese diabetic mice and humans. Clin Exp Immunol. 2010;162(3):407-14.

65. Tian L, Gao J, Hao J, et al. Reversal of new-onset diabetes through modulating inflammation and stimulating beta-cell replication in nonobese diabetic mice by a dipeptidyl peptidase IV inhibitor. Endocrinology. 2010;151(7):3049-60.

66. Fadini GP, Boscaro E, Albiero M, et al. The oral dipeptidyl peptidase-4 inhibitor sitagliptin increases circulating endothelial progenitor cells in patients with type 2 diabetes: possible role of stromal-derived factor-1alpha. Diabetes Care. 2010;33(7):1607-9.

67. Takashima S, Fujita H, Fujishima H, et al. Stromal cell-derived factor- 1 is upregulated by dipeptidyl peptidase- 4 inhibition and has protective roles in progressive diabetic nephropathy. Kidney Int. 2016;90(4):783-96.

68. Reinhold D, Hemmer B, Gran B, et al. Inhibitors of dipeptidyl peptidase IV/CD26 suppress activation of human MBP-specific CD4 + T cell clones. J Neuroimmunol. 1998;87(1-2):203-9.

69. Ding L, Gysemans CA, Stange G, et al. Combining MK626, a novel DPP-4 inhibitor, and low-dose monoclonal CD3 antibody for stable remission of new-onset diabetes in mice. PLoS ONE. 2014;9(9):e107935.

70. Schurmann C, Linke A, Engelmann-Pilger K, et al. The dipeptidyl peptidase-4 inhibitor linagliptin attenuates inflammation and accelerates epithelialization in wounds of diabetic ob/ob mice. J Pharmacol Exp Ther. 2012;342(1):71-80.

71. Shirakawa J, Fujii H, Ohnuma K, et al. Diet-induced adipose tissue inflammation and liver steatosis are prevented by DPP-4 inhibition in diabetic mice. Diabetes. 2011;60(4):1246-57.

72. Ervinna N, Mita T, Yasunari E, et al. Anagliptin, a DPP-4 inhibitor, suppresses proliferation of vascular smooth muscles and monocyte inflammatory reaction and attenuates atherosclerosis in male apo E-deficient mice. Endocrinology. 2013;154(3):1260-70.

73. Leung M, Leung DY, Wong VW. Effects of dipeptidyl peptidase-4 inhibitors on cardiac and endothelial function in type 2 diabetes mellitus: a pilot study. Diab Vasc Dis Res. 2016;13(3):236-43.

74. Sato A, Suzuki S, Watanabe S, et al. DPP4 inhibition ameliorates cardiac function by blocking the cleavage of HMGB1 in diabetic mice after myocardial infarction. Int Heart J. 2017;58(5):778-86.

75. Sauve M, Ban K, Momen MA, et al. Genetic deletion or pharmacological inhibition of dipeptidyl peptidase-4 improves cardiovascular outcomes after myocardial infarction in mice. Diabetes. 2010;59(4):1063-73.

76. Shah Z, Kampfrath T, Deiuliis JA, et al. Long-term dipeptidylpeptidase 4 inhibition reduces atherosclerosis and inflammation via effects on monocyte recruitment and chemotaxis. Circulation. 2011;124(21):2338-49.

77. Satoh K. Dipeptidyl peptidase-4 inhibitors-emerging player for vascular protection. Circ J. 2013;77(5):1156-7.

78. Sameshima A, Wada T, Ito T, et al. Teneligliptin improves metabolic abnormalities in a mouse model of postmenopausal obesity. J Endocrinol. 2015;227(1):25-36.

79. Conarello SL, Li Z, Ronan J, et al. Mice lacking dipeptidyl peptidase IV are protected against obesity and insulin resistance. Proc Natl Acad Sci U S A. 2003;100(11):6825-30.

80. Mu J, Woods J, Zhou YP, et al. Chronic inhibition of dipeptidyl peptidase-4 with a sitagliptin analog preserves pancreatic betacell mass and function in a rodent model of type 2 diabetes. Diabetes. 2006;55(6):1695-704.

81. Cho JM, Jang HW, Cheon H, et al. A novel dipeptidyl peptidase IV inhibitor DA-1229 ameliorates streptozotocin-induced diabetes by increasing beta-cell replication and neogenesis. Diabetes Res Clin Pract. 2011;91(1):72-9.

82. D'Alessio DA, Denney AM, Hermiller LM, et al. Treatment with the dipeptidyl peptidase-4 inhibitor vildagliptin improves fasting islet-cell function in subjects with type 2 diabetes. J Clin Endocrinol Metab. 2009;94(1):81-8.

83. Utzschneider KM, Tong J, Montgomery B, et al. The dipeptidyl peptidase-4 inhibitor vildagliptin improves beta-cell function and insulin sensitivity in subjects with impaired fasting glucose. Diabetes Care. 2008;31(1):108-13.

84. Zhao Y, Yang L, Wang X, Zhou Z. The new insights from DPP-4 inhibitors: their potential immune modulatory function in autoimmune diabetes. Diabetes Metab Res Rev. 2014;30(8):646-53.

85. Kim SJ, Nian C, Doudet DJ, McIntosh CH. Dipeptidyl peptidase IV inhibition with MK0431 improves islet graft survival in diabetic NOD mice partially via T-cell modulation. Diabetes. 2009;58(3):641-51.

86. Jelsing J, Vrang N, van Witteloostuijn SB, Mark M, Klein T. The DPP4 inhibitor linagliptin delays the onset of diabetes and preserves beta-cell mass in non-obese diabetic mice. J Endocrinol. 2012;214(3):381-7.

87. Suarez-Pinzon WL, Cembrowski GS, Rabinovitch A. Combination therapy with a dipeptidyl peptidase-4 inhibitor and a proton pump inhibitor restores normoglycaemia in non-obese diabetic mice. Diabetologia. 2009;52(8):1680-2.

88. Suarez-Pinzon WL, Rabinovitch A. Combination therapy with a dipeptidyl peptidase-4 inhibitor and a proton pump inhibitor induces beta-cell neogenesis from adult human pancreatic duct cells implanted in immunodeficient mice. Cell Transplant. 2011;20(9):1343-9.

89. Kim DH, Lee JC, Lee MK, Kim KW, Lee MS. Treatment of autoimmune diabetes in NOD mice by Toll-like receptor 2 tolerance in conjunction with dipeptidyl peptidase 4 inhibition. Diabetologia. 2012;55(12):3308-17. 
90. Liang J, Leung KK, Lam SY, Leung PS. Combined treatment with a dipeptidyl peptidase-IV inhibitor (sitagliptin) and an angiotensin II type 1 receptor blocker (losartan) promotes islet regeneration via enhanced differentiation of pancreatic progenitor cells. Diabetes Obes Metab. 2012;14(9):842-51.

91. Cabrera SM, Colvin SC, Tersey SA, Maier B, Nadler JL, Mirmira RG. Effects of combination therapy with dipeptidyl peptidase-IV and histone deacetylase inhibitors in the non-obese diabetic mouse model of type 1 diabetes. Clin Exp Immunol. 2013;172(3):375-82.

92. Pinheiro MM, Pinheiro FM, Torres MA. Four-year clinical remission of type 1 diabetes mellitus in two patients treated with sitagliptin and vitamin D3. Endocrinol Diabetes Metab Case Rep. 2016;2016:16-0099.

93. Lima-Martinez MM, Guerra-Alcala E, Contreras M, Nastasi J, Noble JA, Polychronakos C. One year remission of type 1 diabetes mellitus in a patient treated with sitagliptin. Endocrinol Diabetes Metab Case Rep. 2014;2014:140072.

94. Kandasamy N, Lennox G, Annamalai AK, Maguire G, Adler AI. Sitagliptin in glutamic acid decarboxylase antibody-positive diabetes mellitus. Endocr Pract. 2012;18(4):e65-8.

95. Rapti E, Karras S, Grammatiki M, et al. Combined treatment with sitagliptin and vitamin D in a patient with latent autoimmune diabetes in adults. Endocrinol Diabetes Metab Case Rep. 2016;2016:150136.

96. Ellis SL, Moser EG, Snell-Bergeon JK, Rodionova AS, Hazenfield RM, Garg SK. Effect of sitagliptin on glucose control in adult patients with Type 1 diabetes: a pilot, double-blind, randomized, crossover trial. Diabet Med. 2011;28(10):1176-81.

97. Garg SK, Moser EG, Bode BW, et al. Effect of sitagliptin on post-prandial glucagon and GLP-1 levels in patients with type 1 diabetes: investigator-initiated, double-blind, randomized, placebo-controlled trial. Endocr Pract. 2013;19(1):19-28.

98. Hari Kumar KV, Shaikh A, Prusty P. Addition of exenatide or sitagliptin to insulin in new onset type 1 diabetes: a randomized, open label study. Diabetes Res Clin Pract. 2013;100(2):e55-8.
99. Griffin KJ, Thompson PA, Gottschalk M, Kyllo JH, Rabinovitch A. Combination therapy with sitagliptin and lansoprazole in patients with recent-onset type 1 diabetes (REPAIRT1D): 12-month results of a multicentre, randomised, placebo-controlled, phase 2 trial. Lancet Diabetes Endocrinol. 2014;2(9):710-8.

100. Johansen OE, Boehm BO, Grill V, et al. C-peptide levels in latent autoimmune diabetes in adults treated with linagliptin versus glimepiride: exploratory results from a 2-year double-blind, randomized, controlled study. Diabetes Care. 2014;37(1):e11-2.

101. Zhao Y, Yang L, Xiang Y, et al. Dipeptidyl peptidase 4 inhibitor sitagliptin maintains beta-cell function in patients with recentonset latent autoimmune diabetes in adults: one year prospective study. J Clin Endocrinol Metab. 2014;99(5):E876-80.

102. George PS, McCrimmon RJ. Saxagliptin co-therapy in C-peptide negative Type 1 diabetes does not improve counter-regulatory responses to hypoglycaemia. Diabet Med. 2016;33(9):1283-90.

103. Buzzetti R, Pozzilli P, Frederich R, Iqbal N, Hirshberg B. Saxagliptin improves glycaemic control and C-peptide secretion in latent autoimmune diabetes in adults (LADA). Diabetes Metab Res Rev. 2016;32(3):289-96.

104. Guo H, Fang C, Huang Y, Pei Y, Chen L, Hu J. The efficacy and safety of DPP4 inhibitors in patients with type 1 diabetes: a systematic review and meta-analysis. Diabetes Res Clin Pract. 2016;121:184-91.

105. Awata T, Shimada A, Maruyama T, et al. Possible long-term efficacy of sitagliptin, a dipeptidyl peptidase-4 inhibitor, for slowly progressive type 1 diabetes (SPIDDM) in the stage of non-insulin-dependency: an open-label randomized controlled pilot trial (SPAN-S). Diabetes Ther. 2017;8(5):1123-34.

106. Kim YG, Min SH, Hahn S, Oh TJ, Park KS, Cho YM. Efficacy and safety of the addition of a dipeptidyl peptidase-4 inhibitor to insulin therapy in patients with type 2 diabetes: a systematic review and meta-analysis. Diabetes Res Clin Pract. 2016;116:86-95. 